\title{
On the Cultivation of Innovative Sports Talents of Diligence and Wisdom The Speed Evaluation on Laoyi the 100m Champion of 2010 Guangzhou Asian Games
}

\author{
Meifang Zhou \\ P.E College \\ Jiangxi Normal University \\ Nanchang, China \\ 562780393@qq.com
}

\author{
Qilian Cheng \\ P.E College \\ Jiangxi Normal University \\ Nanchang, China \\ chengqilian@sina.com
}

\begin{abstract}
Lao Yi, a student of Jiangxi normal university sports institute, born in hepu county of Guangxi province, is the champions of the events 100 meters and 4 by 100 meters relay in the Asian games held in Guangzhou 2010. In this paper, the human body structure of the elite sprinters in the world and the differences between Lao $\mathrm{Yi}$ and bolt were discussed through the objective historical analysis methods. Results show Lao Yi's diligence and wisdom in the combination of scientific training may be the key factors for his success.
\end{abstract}

Keywords-Sprinters; champions; Asian games

\section{INTRODUCTION}

Beijing time on November 22, 2010 night, Guangzhou Asian games men's $100 \mathrm{~m}$ final, tens of thousands of spectators witnessed the China champion who is born in 1980s and from Jiangxi normal university sports college student Lao Yi to 10 seconds, the audience showed tsunami of celebrations. Cheering people shouted Lao Yi name, a crowd again and again cried "Lao Yi, good", "China's bolt", "Lao Yi made history"; ... . In fact, the meters Lao Yi results is 10 seconds 24, in the eyes of the world the result is not conspicuous. But in the eyes of the Chinese people is attention, deeply gratified, make people on top of the world, why it would be like this? As Jiangxi normal university sports college athletics professional teachers to receive even more inspiration: only the first line, further to the solid line learning, can be more profound understanding to the value of scientific training and practical significance. Through the objective historical analysis and the research, and better summary with diligence and wisdom, the cultivation of the innovative combination method of sports talents will be stated in this thesis.

\section{RESULTS}

\section{A. The human body structure is the first element to decide the speed of runing}

Run, the basic form of activity, and to which decided run speed is main or repose constantly improve modern body structure and athletic ability of development, constantly improve the runway in modern facilities and scientific training relative stability conditions, decided to run speed of the first elements, it is human body structure of the individual characteristics. Especially the short run depends on the reaction rate, sprinting acceleration, and keep the pace of increase, increasing run speed and finish the whole process, and the way of running pace, depends on the runner's height and run the technical level, access to data, because people living the regional environment and ethnic morphological structure, different body small Asian and tall America (North America in the Caribbean), and Europe, Africa, Oceania are there are some differences. In 2009 in Berlin track and field world championships in the field, the men's meters final track without a Asian, Asian only Qatar's FeiLang sith ran into ten seconds, Japan's Iraq Donghao company best results only run 10 seconds, not run into ten seconds of the Chinese people, has been blocked in ten seconds of hurdle, but best result China meters record holder Zhou Wei create ten seconds 17; And we still far behind America and North America Jamaican, bolt have created the world record of seconds and the tail (figure 1).

According to relevant data displayed and experts determination, Jamaican bolt has 1.95 meters height advantage, only step and run 100 meters, the average step close to 2.45 meters [1], the biggest steps up to 2.70 meters [1], bolt 30 meters later, often by large stride and amazingly stride length win the game, and his face to face competitive 1.80 meters height athletes, generally need to 42-43 step to run the meters, bolt win it To win in the height advantage, especially the way Hou Cheng ran, ran faster and faster, that is to say, stride length and stride determine his running speed. Around the world m record 
of all the continents, Asia only card dall Francis created 9 seconds 99 Asian record, still lags behind tall America (North America), Europe and Africa, according to the survey data showed that by the end of 2001, the Jamaican population for 2.62 million black and mixed is $90 \%$, the north by the statistics

Graph one: intercontinental meters results hint curve

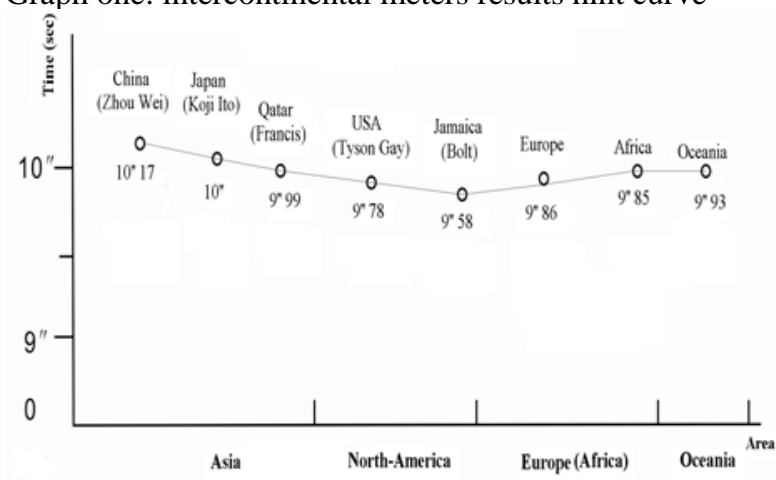

Beijing Olympic Games and track and field athletes name Jamaica, and human sprinter specialist, $76 \%$ of the Jamaican occupied the short run territory, it is human body structure, including the shape and fast power muscle fibers impulsion of genetic genes. However, with the development of modern science and technology, not only can promote gene mutation, and will also promote the human more diligence and wisdom phase structure of scientific training, in order to promote the development of human speed quality and ascension.

\section{B. Lao Yi and bolt differences comparison}

When Lao Yi in Guangzhou Asian games track and field competition in the final meters, with ten seconds and achievements, won the championship, the boiling celebrations, it is an understanding, because it put an end to China to participate in the Asian games since 36 years, men's meters without coronary history. People enthusiastically praise Lao $\mathrm{Yi}$ is "creating history", is "China's bolt"...... , in fact, Lao Yi heart the most clear, "I am Lao Yi, not bolt", Jiangxi normal university sports college students in Guangxi, and Chen Wenzhong track team coach to accept the training system; As the first time on behalf of the Chinese to Guangzhou Asian games, the goal is to play to the technological level, meters break the record, "I didn't think of the Asian games to win, just in the rival competition, but I ran out to the rhythm of the match "[2]. Someone cries "Chinese bolt", that's just form similar, starting response is slow, the gun, Lao Yi penult started, the reaction time of 0.170 seconds, To compete with competitive HaErXi, Habib and Nashiri starting at all lead, Lao Yi three steps before due to the center of gravity is slightly low, thus not fully rushed up, and Lao Yi's confidence, with very strong acceleration run, at the end of the second HaErXi has narrowed the gap, after twenty meters Lao Yi completely broke out, and take the lead in the title and, give full play to the advantage of Lao Yi spurt, as bolt starting slow, spurt pursued and beyond
"Bolt type" - meter run similar method. This is only form similar, however does exist substantial differences.

Everything around the world is relative and depend on each other, including the human body movement speed, the contemporary world $\mathrm{m}$ air bolt, gay and Powell three the fastest male athletes, people say meters "big three" between them, who also is not absolute winner, bolt from August 16, 2008 Beijing Olympic Games, in the past two years after winning streak has 14 times; However, but in August 2010 IAAF diamond league's song, the station's $100 \mathrm{~m}$ "air war", the United States's guy to 9 seconds 84 champion, but in the 15th combat bolt end for 15 straight dream, with only 9 seconds 97 ran meters, end the unbeaten myth [3]. Bolt actually lose in where? According to expert analysised after the main lose in the technology not gay, any things all attitude every coin has two sides, when bolt has been the height stride and spurt hair force advantage, once was the perfect technical flow control, that guy will break flash unbeaten myth. The United States sprint star green, give a general guy technology of high evaluation, the technology is more perfect, guy in the reaction time, the body coordination and cohesion technology link to wait, all similar with the United States university athletics textbook technical movement, like track and field experts say "academism technical" action. The basic technology is concerned, China's sprinter is only 7.72 meters Lao Yi regardless of swing arm, stride length and body posture are approximate guy textbook of technology, fully reflected in Guangzhou Asian games in the final meters, turn to run, technical requirements on foot before in the center of gravity of the vertical front, the former pedal down; Landing legs quickly the peg-leg paint joint buffer ankle, make the body quickly move through the vertical line, and actively stretch hip, knee, ankle, alternate after completion of the pedal, then push your strong, swinging leg thigh carried high, make the body keep forward speed; The way of running pace, depends on the runners corresponding height. 1.95 meters height of the bolt, his knee can also carry some higher, to meet the technical requirements, Lao Yi by height limit, but the technology is higher than the bolt's. Lao Yi with perfect technology ditching one opponent, the first finish and win. As a teenager Lao Yi after 80, Jiangxi normal university physical culture institute students, in the Guangxi Zhuang autonomous region in Hepu county BeiHaiShi sports school, accept the track and field sprint specific training duration is not long, from 2007-2011 Lao Yi every season and bolt meters performance curve, the separation to gradually narrowed, shows that Lao Yi technical flow is mature. 


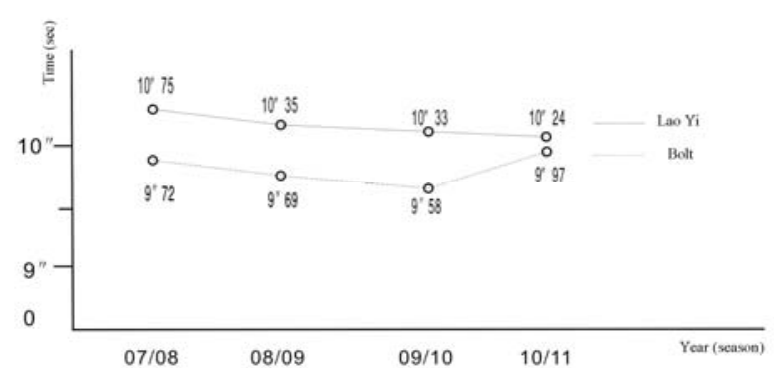

However, anyone who always difficult to down Jamaican bolt great strides and the gift of 1.95 meters height, $88 \mathrm{~kg}$ weight, rapid contraction of muscle, the typical stride type and the way to run ace in the hole and congenital conditions, masking his "rough" technology, only to improve technology, flash still can restore peak form.

\section{Diligence and wisdom of the combination of scientific training}

"The scientific concept of development, the first is to develop the essence, the core is the human-oriented" [4]. People-oriented as the state's basic concept, it fully reflects "people is to create the basic driving force of history, no matter in China's socialist economic construction, or development of social material civilization and spiritual civilization construction, including health education and the development of competitive sports, particularly the athletic sports of China the most interesting track and field meters speed project, because it relates to the human body speed quality comprehensive evaluation. As China's economic construction and the development of science and technology, make the best use of the latest achievements of world science and technology innovation and technical reserves, adhere to independent innovation, make full use of the advantages of spurt hair force, and to realize the great-leap-forward development of science and technology, implement people-oriented, give full play to people's enthusiasm and creativity, with diligence and wisdom, the method of combining the implementation of scientific training, push out of an independent innovation road, in 2010 Guangzhou Asian games of the meters in 80, after Lao Yi player of the road of innovation, with ten seconds and won the meters champion, rewrite the 36 years China without coronary history." [5]

A national sports competition level, only then has the formidable independent innovation ability, can in the international sports competition to grasp the opportunities, and to win the initiative. "The real core technology, the key technology is can't buy"[4], and must rely on independent innovation. China table tennis sport created reverse penhold backhand, table inside "choose", "screw" technology innovation, make our country in the international table tennis competition prevalent; The 110 meter hurdles, Liu Xiang the starting by eight steps into seven steps on column technology, ran out of the 13 seconds the best performance of the season, and this is the victory of the technical reform. M speed project, because of the physical structure conditions, has been Asian weaknesses, in Asia and Chinese weaknesses, we must be integrated with their own characteristics, and strengthen the way run spurt hair force core technology research, guy master spurt hair force technology unique skill after, win over flash bolt is the most typical cases, and China Lao Yi teenager with 1.72 meters height, play fast frequency, spurt advantage, and in just two years time, in Guangxi excellent team coach Chen Wenzhong coach under coach, meters results by 10 seconds 75, up to ten seconds, and the speed of 0.54 seconds (table 1 )

TABLE I. TABLE 1 2008.11-2010.6 LAO YI METERS ACHIEVEMENTS STATISTICS（S）

\begin{tabular}{|c|c|c|c|c|c|c|}
\hline \multirow{2}{*}{$\begin{array}{l}\text { Game } \\
\text { level }\end{array}$} & \multirow{2}{*}{$\begin{array}{c}\text { The } \\
\text { national } \\
\text { track and } \\
\text { field } \\
\text { Grand } \\
\text { prix }\end{array}$} & \multicolumn{2}{|c|}{$\begin{array}{l}\text { The national } \\
\text { track and field } \\
\text { competition }\end{array}$} & \multicolumn{2}{|c|}{$\begin{array}{l}\text { Chongqing } \\
\text { championship }\end{array}$} & \multirow{2}{*}{$\begin{array}{c}\text { Hoisti } \\
\text { ng } \\
\text { speed }\end{array}$} \\
\hline & & $\begin{array}{l}\text { Kun } \\
\text { shan }\end{array}$ & $\begin{array}{l}\text { Chong } \\
\text { qing }\end{array}$ & $\begin{array}{l}\text { prelimi } \\
\text { nary }\end{array}$ & final & \\
\hline Grade & 10.75 & $\begin{array}{c}10.3 \\
9\end{array}$ & 10.37 & 10.32 & $\begin{array}{c}10.2 \\
1\end{array}$ & 0.54 \\
\hline
\end{tabular}

The famous sprinter star green high praise gay, regardless of the reaction, body coordination and connection between the technology link, it conforms to the American college of track and field course is the most ideal teaching section type template. The so-called textbook technology, it is through the long-term scientific summary constantly special technology practice effect, written into university athletics textbook, it must conform to the technical specifications of the accepted standard action, carries on the comparison analysis and evaluation. Professional sports college must to the practice study, strengthen the theory and practice research, in order to better improve the professional and technical teaching level.

\section{CONCLUSION}

Lao Yi comes from Guangxi Beihai hepu county is now studying in Jiangxi normal university sports institute, is engaged in the track and field short run special learning and training; Because Lao Yi from living in Guangxi Beihai green clear water, climate pleasant, the survival of natural oxygen bar is to provide a good living environment, not only is beneficial to people's health, but also helps to train the anaerobic metabolism ability. Lao Yi from love running and running game activities, has formed the good exercise habits, and in 2005 Guangxi sports school track and field team Lao Yi start formal short run special training, 2008 to participate in the national league for 10.75 seconds, not into people's eye, in 2009 the national track and field general the race in 10.35 seconds, get the second name, in August 2010, the Asian games Xuan Bo "in 10.31 seconds was elected to the national track and field team finally to 10 seconds and won the Asian games in Guangzhou 100 meters and 4 by 100 meters relay champions. By Lao Yi figure limits, from their own reality, give full play to its own advantages, steps on the basis of 
relative stability, strengthen the training frequency, and give full play to the guy type spurt hair force technology advantages, improve their running speed, and to take part in the international competition of the opportunity to learn and summarizes the recent international competition experience, Shanghai international diamond league, Lao Yi and world sprint the three musketeers Powell face to face competition, is a summary and promote one's own best opportunity, believe that Lao Yi's diligence and wisdom in the combination of scientific training basis, will be a new effect.

\section{REFERENCES}

[1] Zuo Wei. theory bolt sports talent and diligence Hubei sports science and technology, 2009 (2) P176-178

[2] reporter achievement honor Beijing time 2010.11.22 late Guangzhou reported

[3] Xu Huiju.sports news: perfect technology break unbeaten myth Nanchang 2010.8.8 evening news

[4] Hu Jintao .hold high the great banner of socialism with Chinese characteristics, to capture the comprehensive construction well-off society and strive for new victories (2007.10.15)

[5] news reports Lao $\mathrm{Yi}$ is our bolt the Yangcheng evening news 2010.11.26 